\title{
The Influence of Extensive Reading upon Vocabulary Acquisition
}

\author{
Lijun Yang \\ School of Business and Trade \\ Huanghe Science and Technology College \\ Zhengzhou, China \\ e-mail: 379630960@qq.com
}

\begin{abstract}
The extensive reading is one of the efficient methods which may be conductive to the vocabulary acquisition of the second language; the process of studying English nearly can be regarded as a process of unceasing and circulating vocabulary acquisition. The extensive reading's increases are very helpful to the readers who wish to add vocabulary and understand accurately the profound significance of words and expressions under the linguistic environment of specific context. The ways of the influence and promotion of extensive reading on the vocabulary acquisition may include many in fact, if such ways can be used effectively, the positive cycle of the extensive reading and vocabulary acquisition may be promoted; simultaneously it is also necessary to adopt some suitable strategies for the extensive reading.
\end{abstract}

Keywords—extensive reading; vocabulary; acquisition

\section{INTRODUCTION}

The glossary is one of basic elements of studying language and is the basis of all activities of language. Such following skills of language: listening, speaking, reading, writing as well as translation and so on all depend on the words and expressions closely. As is well know that the learners of foreign language are easy to write the wrong glossary; the most difficulty for their listening is also the words and expressions. Thus vocabulary acquisition is playing the decisive role in the entire process of language learning and still has been a central task of the foreign language's study. In recent years the researchers have carried on the discussion and the empirical study to vocabulary acquisition from different angles, some scholars researched the psychological feature of vocabulary acquisition, or psychological words and expressions, some scholars researched studying strategy of vocabulary acquisition, also some researchers try another method from the angle of incidental vocabulary acquisition to make the research into the supplementary acquisition of foreign language's glossary. There are case study, qualitative investigation and quantitative investigation. The vocabulary acquisition makes influence on the reading speed directly and the reading speed may be improved through massive and widespread reading training. So there is a close relation between the vocabulary acquisition and the extensive reading. If you master the reading skills, you can read more smoothly and grasp more words and expressions. The English learners have difficulty to keep new English words firmly in their mind effectively, so it is a hard problem for them to grasp enough words and expressions and it has further also affected their English study. In a word, it is very necessary to help English learners promote the vocabulary acquisition through the extensive reading.

\section{PROBLEMS OF VOCABULARY ACQUISITION}

Vocabulary acquisition refers to the process or result of grasping well certain aspect of or the whole language in the applied linguistics. Generally speaking, a word acquired refers to keeping abreast of its complete knowledge. Many scholars believe that a word acquired including the following aspects: the cognition of its written and spoken form; the word can be momentarily recalled and be related with the suitable object or the concept; the suitable grammatical form can be used; oral pronunciation is very clear; it can be spelt correctly according to its appropriate matching and can be utilized according to its suitable official degree; the connotative meaning and the associative meaning of the word may be realized. The majority of English learners think the vocabulary acquisition is the biggest barrier in English study, the word is hard to be remembered effectively and permanently, the biggest obstacle is lacking vocabulary. At present reading comprehension accounts for the very great proportion in the entire test of each common kind of English language's test, such as College English Test 4, College English Test 6, GRE, as well as TOEFL. The question of new words often affects the reading speed and the answer's accuracy of examinees. Because they do not know the words, they can not understand what they have heard or read, to say nothing of writing and translation. This poor foundation of glossary will directly restrict the development of many abilities such as listening, speaking, reading, and writing and so on. Therefore, when studying the second language, regardless of how they grasp well its grammar and how they master the pronunciation attractively, the learners do not have enough glossaries to express each kind of meaning, then it will be hard to realize the communication of the language. After being investigated the main causes of few vocabulary as follows: First, the International Phonetic Alphabet can not be accurately confirmed and read, which leads to the words and expressions can not be read correctively; all these bring the barrier to the glossary's grasping and the difficulty of remembering words increases. Second, 
memorizing methods of new words should be not appropriate, that is the mechanical memorizing. Although the massive time need be spent, it is easy to forget the words and expressions which are remembered with great difficulty. When once reading an English article, the English learner still thought that everywhere is the new word. Third, the quantity of outside reading is not enough, ordinarily regarding the English learners contact very little materials of extensive reading, less reading will result in more new words and expressions; more new words will lead to the less desire of reading, it is a vicious cycle. Hence the vocabulary is biggest foundation of learning language to make the communication. We can say the process of studying English nearly is an unceasing process of vocabulary acquisition, including memory, accumulation as well as utilization of words and expressions.

\section{INFLUENCE OF ENGLISH EXTENSIVE READING UPON VOCABULARY ACQUISITION}

The English extensive reading may affect and promote vocabulary acquisition. English extensive reading affects and improves the vocabulary acquisition mainly through the following several ways.

\section{A. Judging the Meaning of the Words from Linguistic Environment and Logic Reasoning}

Through the linguistic environment and logic reasoning of the extensive reading materials the meaning of the new words can be estimated. Then the vocabulary acquisition can be affected and promoted. For example: "Young people who are just starting their households often spend some of their money on appliances, for instance, stoves, washing machines and televisions." The meaning of "appliances" can be inferred from the above mentioned "stoves, washing machines and televisions." The morphology is prohibited from separating from the concrete linguistic environment and according to own attempt to guess the meaning of the words purely. In addition this kind of old words containing new meaning should arouse enough attention of the English learners, the meaning of the words and expressions must be made the judgment according to the linguistic environment, nor has it been assumed as a matter of course.

\section{B. Judging the Meaning of New Words from Context}

We may avail the words and expressions of the context to acquire vocabulary. First, we can make the adjustment according to antonym of the context. For example, "Unlike his gregarious brother, John is a timid boy, who does not like to talk with other people or to go to parties." this "unlike" is a signal which expresses the counter meaning of words, indicates new word "gregarious" and "timid" have the opposite meaning, from this we may infer the meaning of "gregarious" is "sociable". Second, we can avail the synonym and near synonym in the context and guess this new words' meaning through these words. For example: "Number, such as $1,2,3,4,10,200,3000$ are called whole number, in or integers." "integers" in this phrase is a new word but we may know its meaning is "whole number" through its synonym in the context.
In the process of reading, the English learner had better reorganize each kind of antonym, near synonym and the synonym. Such near synonym as: quit-stop, proof-evidence, damaging-harmful. Such antonym as: include-exclude, approve-disapprove, passive-active. Especially antonym with the prefix, for example: Prefix dis- expresses the denial, belief-disbelief, honest-dishonest; prefix in- expresses the denial, appropriate - inappropriate, correct-incorrect, prefix un- expresses the denial, certain-uncertain, fit-unfit. When remembering a new word, the English learners should simultaneously remember those words which are relevant with them, for example "flex" may be expanded as "flexible, flexibility, flexibly, inflexible", like this, it may be very easy for English learners to remember quickly the words as far as possible by the comparison and making a connection.

\section{Judging the Meaning of Words by Analogy}

The learner can know or even acquire the meaning of the words according to the analogy of words and expressions in the context. What is the analogy of words? For example: From blue-collar workers and white-collar workers to infer naturally grey-collar workers and pink-collar workers, gold-collar workers, and realize the latter two means more dignity of profession, higher economic status than the former, but with reference to open-collar workers, the meaning of the words should be understood by analogy because these people may put on casually at home through the computer terminal to work, such analogy may facilitate the memory of English learners. Because analogy of words combines marvelously the isolated glossary; puts the roots, the synonymy, the counter meaning, the related words and easy confusing words together to implement the understanding and remembering; thus the speed of remember not only greatly is sped up, but also confidence and interests of the learners have been enhanced. Which kind of strategy is the best for the English learners is decided by the feeling and exploring in the reading practice.

\section{Mastering the Words by Prefixes, Suffixes and Roots}

The prefixes, suffixes and roots in this part are different from the above mentioned; the English learners can master the new words by prefixes, suffixes and roots in the extensive reading and avail them to remember the words and expressions. Prefixes and Roots are usually able to express the meaning to some extent, and suffixes main decide lexical category. In English glossary there are large quantities of compound words which are composed of two stems as well as derivative words which are composed of the stem and the prefix, the suffix, or the suffix. The compound word's stems are the basic glossary which could exist independently, the meaning of the word "compounds" the word's meaning. Such as pillowcase, tablecloths, the meaning of them can be guessed correctly and easily. The overwhelming majority of long words which bring English learners difficulties are derivatives, so long as we can identify the meaning and form of these words' affix and stems, then their morphology, meaning as well as lexical category can be analyzed. Such as the suffix ist expresses this kind of person who are engaged in some profession, then many glossaries are very easily be judged, 
such as psychologist, geologist, numerologist. The suffix logy or -ology means the "study of ...", if the English learners can understand some stems' meaning, then a word which is composed of this stem and this suffix can be acquired very easily. Such as the stem bio- means the life, and then the compound of bio- and -ology is biology refers to a study of life; the phon- means the sound, the compound of phon- and ology is phonology refers to a study of phonetics. So if you know the meaning of common suffixes, prefixes and roots, you may find the key to understand or acquire the words in the extensive reading. Then let us discuss the derivative. Supermarket, superpower, superman and so on are all derived from prefix super-. Such as the suffix -cide refers to killing or killer, so as the insecticide refers to the "things which kill the insects", and sui- in suicide means "self", therefore we are able to know the "suicide" means "to kill oneself". Through extensive reading, we can strengthen the memory of words by prefixes, suffixes and roots. In the reading materials there are so many quantities of compounds or derivatives that the English learner have enough opportunity to practice and acquire the vocabulary.

\section{E. Grasping the Words by Punctuation}

In the extensive reading there are many punctuations, so English learners also can avail the punctuation to understand the meaning of the words. For either the words, context, analogy of words and logic reasoning can facilitate the vocabulary acquisition, or the punctuation can do it also. The punctuation marks the clue, the comma, the colon, the dash and the parenthesis etc. all can be regarded as the clue of understanding the words. Such as, "numerology- using numbers to predict the future." From this phrase we may know that the contents after dash may be the explanation of "numerology".

\section{STRATEGIES OF PROMOTING VOCABULARY ACQUISITION THROUGH ENGLISH EXTENSIVE READING}

We have found the extensive reading may provide the information as much as possible to promote the vocabulary acquisition. It is very helpful to increase the vocabulary acquisition and the glossary's long-time memory on the basis of sound, shape and meaning to strengthen the memory of words in the extensive reading. It is a process of raising independent ability and a vital significance to raise English proficiency. In the meantime there are some questions and strategies that should be paid attention to.

\section{A. Some Questions that should be Taken Notice of}

When promoting the vocabulary acquisition, the English learners should take note of the following aspects.

1) Selection of extensive reading materials. First, the extensive reading material's difficulty must be suitable; the English learners may choose the contents in the extensive reading textbook or choose the publication, the magazines and other materials. The material's difficulty should be higher than one's own English degree slightly. Next, learners may read massively the materials which they are interested in as well as the topic which they themselves pay more attention to. Such selection according to various people's fancy will facilitate the promotion of English vocabulary natural acquisition and longterm memory of the person. At last, English learners should read many English materials as far as possible; in addition they should pay more attention to the meaning and the usage of English glossary under the specific semantic background in their process of reading, and gradually acquire the morphology and the word meaning of the English words and expressions.

2) Deep reading. If people wish to understand thoroughly a specialty or some aspect of knowledge, ten or more such specialized articles should be read at least, then the reading speed can be increased and the reading skills which have been studied originally can be used from strangely to naturally, this specialized general words and meaning can be understood gradually; that is from the change of quantity to the change of quality, first is quantity, next is quality. In the process of deep reading, English learners had better not read a book or a very long article, because it is so difficult to read them thoroughly and form the feeling of harvest that your enthusiasm of reading will be attacked. Read the short article as far as possible and gain the key professional glossary as well as the article's main idea. Read the similar articles of special topic, because similar or the related new glossary may appear frequently, then the speed of reading will relatively be quick, and it is helpful to your confidence and new glossary's strengthening.

3) Practice of reading. The practice of reading refers to the applications of reading practice. In the work or daily life you may meet frequently such situations that should understand or search the related material of overseas; this requests you to demonstrate your reading level. The people often said that a quick and poor reader is useless in the age of information, a slow reading similarly is also useless, therefore you do not need to guess the words and look up in a dictionary too many times in practice, we should acquire the information in the article which we read and. Thus it can be seen that it is the most important thing to raise the reading speed, at this aspect, the English learner must raise one kind of sensitive consciousness to the glossary. Once a new word comes out, you should infer its meaning as soon as possible according to the related knowledge and skills which you have studied as well as the context and the suffix or prefix etc., such as "contranatural", you should understand this word immediately is composed of contra+ natural; or "eastward" is composed of east and ward if you do not know the whole words. Through flexibly applying your skills in practice, you can solve the reading speed problem effectively. Of course the English learner must clarify the minority of key words' meaning finally.

\section{B. Methods of Reading}

Because English teaching spends much time on explaining the character, the words and phrases in China at present, the level of listening has been enhanced in recent years, but the understanding ability of vocabulary has dropped, some English reading is also based on the existing vocabulary. After entering the university, the way of teaching has changed. Teachers' teaching covers everything superficially but deals 
with nothing in depth. The students should form a habit themselves of understanding or studying, nobody forces you to study this or that. Teachers often encourage students to look for the respective method of studying frequently. The enhancement of English reading ability will bring the very big help to future study and the practical application, so the relations between reading and glossary are supplementary to each other and promoted mutually. So learners should increase the vocabulary through extensive reading, the more vocabulary they grasp, the easier reading they can enjoy.

1) Preparing reading. Namely you should fix your thought on the contents of your reading materials and do not wander off, it is not easy for you to do it in a short time. Because person's thinking activity is quicker than the reading speed, if you can not concentrate promptly your thought on the reading contents, you will be spirited away easily, until your thinking come back again many time has been wasted. You must find its subject as soon as possible: the first and last phrase of a paragraph that you should read first, they often are the paragraph's subject sentences; the first and last paragraph of the article should be read first too, they summarize central thought of the article often.

2) Reading with problems. Turn the big title and small title into questions, look for the answer in the article; or read off the conclusion then look for how this conclusion is got in the article. This part will involve the question of vocabulary, if you run up against the words and expressions which you do not know, you had better not look up in a dictionary first, but you should guess. Because the goal of reading is to acquire the knowledge and the information primarily, next to expand vocabulary; furthermore you will spent much time on looking up in a dictionary. Because although you have looked up, you still need to guess what kind of meaning should be chosen. Therefore once you meet new words, you should guess the meaning first. There are many methods to guess words which have been introduced in the former of the article. Regarding the key words in the article, if you do not understand them you could not understand the article; you must look up them in a dictionary to examine whether you guess the meaning is right or not. But what you have looked up should be thought first, only after that you can know the pronunciation and the meaning well, remember them firmly as well.

3) Inspection of reading. This method means to record the central thought and general ideas of paragraph of the reading materials with ones own words, among them the key words and the phrases which are looked up in the dictionary must be written down, it is necessary for the English learners to have a written understanding to them.

4) Consolidation of reading. Namely you may have the plan of review to consolidate your vocabulary acquisition; you can review what you have written down one time at every week, read the record and review what you have read. It is the most important thing to review the new words what you have read in the article. Along with the deep studying, the knowledge which you should remember is getting more and more, without review you can not acquire the words enough. In the meantime you can read aloud the new words, and then your memory of the words can be consolidated.

\section{CONCLUSION}

The English extensive reading is one of skills of studying English which include listening, speaking, reading, writing, it is the most essential requirement to grasp this kind of glossary then to understand the words' meaning. Through the study of English formation of words, more thinking, looking up the key words in a dictionary and remembering efficiently the words, then the comprehending type of vocabulary may be enhanced, but regarding correct understanding and explanation of the word's meaning, the context and the concrete linguistic environment need to be considered. When reading, Learners especially should pay attention to the "links of the preceding with the following" and achieve mastery through a comprehensive study. Learners who integrate the context or the concrete linguistic environment to carry on reading can judge and understand accurately the author's intention and the meaning of words and expressions. Thus they can quickly study well the glossary in the extensive reading and save much time, but does not need to look up the dictionary once there comes out a new word. In brief English reading is very important, it helps to expand vocabulary, enriches the expression and raises the ability of analysis, judgment, induction, and gains accurate information. The suitable strategies should be adopted, for instance the selection of appropriate extensive reading materials, the use of appropriate extensive reading methods. All in all the more extensive reading you read and practice, the more vocabulary acquisition you can get.

\section{ACKNOWLEDGMENT}

I would like to give my heartfelt thanks to many people for their help in my academic studies over the past years. My deepest gratitude to my family, thanks for their kindness, patience, encouragement. Thanks to my school that has give me this delicious opportunity. And thanks to my dear friends who have given their great help to me in my research.

\section{REFERENCES}

[1] Cronbachl. J. An Analysis of Techniques for Diagnostic Vocabulary Testing [J]. Journal of Educational Research. 2002, (36).

[2] Parry. K. Vocabulary and Comprehension: Two Portraits [J] . 2006, (21).

[3] Peter Lisca, The Wide World of John Steinbeck [M]. New York: Rutgers University Press, 2006. 